\title{
A CONSTRUÇÃO DOS SABERES DOS TRABALHADORES DA PESCA ASSOCIADOS A COLÔNIA DE PESCADORES ARTESANAIS Z-16 DE CAMETÁ- PA
}

\section{CONSTRUCTION OF KNOWLEDGE OF FISHERY WORKERS ASSOCIATED WITH FISHERMEN COLONY OF CRAFT Z -16 CAMETÁ -PA}

\author{
Adenil Alves Rodrigues ${ }^{1}$ \\ Egídio Martins ${ }^{2}$
}

\section{RESUMO}

Este estudo questiona como o trabalho dos pescadores da Colônia de pescadores artesanais Z16 de Cametá- Pa, Brasil estar a materializar nesses sujeitos um conjunto de saberes? O objetivo é analisar os saberes construídos no trabalho da pesca. Na metodologia foram usados entrevistas semiestruturadas (MICHELAT, 1985), análise de conteúdo (FRANCO, 2007) e o materialismo histórico dialético (MARX, 2008). Os resultados evidenciam que os saberes dos pescadores são produzidos no trabalho da pesca e que esses são repassados de geração a geração. A conclusão aponta que os saberes se materializam através de relações dinâmicas que os pescadores estabelecem com o mundo da pesca da qual estar envolvido um conjunto de elementos entre os quais a cultura, a afetividade, o trabalho e o próprio saber.

PALAVRAS- CHAVE: Saberes - Trabalhadores da pesca - Colônia de Pescadores Artesanais Z-16 de Cametá- Pa.

\section{ABSTRACT}

This study asks how the work of the fishermen colony of artisanal fishermen Z-16 from Cametá- Pa, Brazil materializes these subjects a set of knowledge. The objective is to analyze the knowledge built in the work of fishing. In the methodology was used mid-structured interviews (MICHELAT, 1985), content analysis (FRANCO, 2007) and the historical and dialectical materialism (MARX, 2008). The results evidence that fishermen's knowledge is produced in the work of fishing and these are passed on from generation to generation. The conclusion shows that the knowledge they materialize through dynamic relationships that the fishermen establish with the fishing world of which is involved a set of elements such as the culture, the affection, the work and the knowledge itself. 
KEYWORDS: Knowledge - Fishery Workers - Colony of artisanal fishermen Z-16 Cametá$\mathrm{Pa}$.

\section{INTRODUÇÃO}

O presente estudo tem por objetivo analisar os saberes construídos no trabalho dos pescadores associados na Colônia de Pescadores Artesanais Z- 16 do município de Cametá3, Estado do Pará, Amazônia, Brasil ${ }^{4}$. Para isso, levantamos como problemática o seguinte questionamento: como o trabalho da pesca, que em comum os trabalhadores da Colônia de pescadores artesanais Z-16 de Cametá-Pa executam, estão a materializar nesses sujeitos um conjunto de saberes?

No que tange a metodologia, neste estudo foram feitas entrevistas semiestruturadas (MICHELAT, 1985) junto aos pescadores que estão associados a Colônia Z16, Estado do Pará, no município de Cametá e que estão diretamente atuando no mundo do trabalho da pesca mantendo uma rede de relações, sociais, políticas e culturais com tal trabalho. Para análise dos dados, epistemologicamente nos pautamos no materialismo histórico dialético ${ }^{5}$ (MARX, 2008) tendo a análise de conteúdo (FRANCO, 2007) como procedimento de apreciação dos mesmos. Também nos pautamos em uma revisão de literatura que nos permitiu analisar as categorias saberes e trabalho enquanto produtos do movimento histórico- social dos homens.

Estruturalmente, organizamos esse texto em três seções: na primeira buscamos discutir o Trabalho, onde revisitamos essa categoria assumindo essa não enquanto atividade abstrata alienante, mas sim enquanto atividade concreta que permite ao homem dominar a totalidade do saber- fazer que se constrói no movimento dinâmico das relações humanas. Aproveitando as discussões traçadas na primeira seção, desenvolvemos a segunda, onde trataremos especificamente da categoria saberes. Nessa seção buscamos definir os saberes a partir das relações dos homens e suas vivencias práticas com o mundo.

Na terceira e última seção, nos detemos nas análises das entrevistas feitas com os pescadores da Z-16 de Cametá. Procurando enxergar a construção dos saberes a partir dos movimentos dialéticos, nessa seção analisamos a formação dos saberes dos pescadores através do trabalho desenvolvidos por esses sujeitos. E por fim, expomos nossas considerações finais. 


\title{
O TRABALHO
}

Para analisar como os saberes dos pescadores se materializam a partir do trabalho da pesca, optamos por iniciar nossas reflexões primeiramente conceituando o que é o trabalho. Contudo, antes de fazermos tal conceituação, é prudente que tenhamos claro que para essa categoria existem as mais diversas concepções e abordagens, entre as quais, a burguesa, que estrutura "[...] uma concepção ou representação de trabalho que se iguala a ocupação, emprego, função ou tarefa [...]” (FRIGOTTO, 2012, p. 21), o que nos conduz a, desde já, deixarmos claro qual a concepção que vamos nos pautar para discutimos tal categoria.

Para tratarmos da categoria trabalho, nesse texto vamos assumir como corrente epistemológica, a concepção materialista histórica dialética, ou melhor, vamos nos utilizar das concepções defendidas por Marx, para quem o trabalho é

\begin{abstract}
Antes de tudo, [...] um processo entre o homem e a Natureza, um processo em que o homem, por sua própria ação, media, regula e controla seu metabolismo com a Natureza. Ele mesmo se defronta com a matéria natural como uma força natural. Ele põe em movimento as forças naturais pertencentes a sua corporalidade, braços e pernas, cabeça e mão, a fim de apropriar-se da matéria natural numa forma útil para sua própria vida. Ao atuar, por meio desse movimento, sobre a Natureza externa a ele e ao modificá-la, ele modifica, ao mesmo tempo, sua própria natureza (MARX, 2008, p. 211).
\end{abstract}

Conforme a definição de Marx (2008), o trabalho vem se caracterizando como mediação que se coloca entre o homem ${ }^{6}$ e a natureza ${ }^{7}$, onde aquele (o homem) para suprir suas necessidades materiais se apropria da natureza transformando-a e suprindo suas indigências. Contudo há de se considerar nessa relação que o trabalho não é mera transformação da natureza, pois, o homem ao agir sobre a natureza modificando-a modifica-se a si mesmo. Ou seja, para além de uma simples interação, ao condicionar a natureza as suas necessidades transformando-a, o homem também condiciona-se a natureza e a partir de uma relação dialética transforma a sua própria natureza humanizando-se e recriando-se a cada interação.

Nessa lógica defendida por Marx (2008) o homem, através do trabalho, supre suas necessidades mais imediatas e desenvolve outras necessidades mediatas que faz com que a relação homem natureza seja uma constante e sempre mediada pelo trabalho. Assim, é através do trabalho que o homem desenvolve sua essência humana, pois, ao colocar em movimento sua corporeidade para se apropriar da matéria natural modificando essa de acordo com sua vontade, transfere para o objeto construído, sua objetividade fazendo com que o produto do 
seu trabalho seja um reflexo humanizado daquilo que o homem é. Nessa relação também há de se considerar que ao construir os materiais do qual tem necessidade, apreende e aprende na relação e assim desenvolve sua subjetividade modificando-o a si mesmo.

Visualizado a partir desse aspecto, o trabalho humano assume uma perspectiva histórico ontológico. Histórico porque é resultante da interação dos homens com seus pares e desses com a natureza, interação essa que vem se dando através do tempo e espaço e que como resultado deixa para as gerações posteriores um conjunto de valores, atitudes e conhecimentos (bens imateriais), e não só isso, mas também, os próprios bens materiais resultantes das interações que o homem estabelece com a natureza, ou seja, os produtos que em estado natural são transformados através do trabalho humano em coisas úteis para suprir as necessidades do homem como, por exemplo; utensílios, roupas, moradias, ferramentas, entre outros.

Assim, ao receberem esse conjunto de bens materiais (utensílios, roupas, casas, ferramentas, entre outros) e imateriais (valores, atitudes e conhecimentos), as novas gerações de homens, não apenas recebem um legado deixado pelos seus antecessores, mas sobre tudo, assumem a possibilidade de desenvolverem outros conjuntos de bens materiais e imateriais, e mais que isso aprende a superar as deficiências e limites que as gerações anteriores não ultrapassaram e dessa forma desenvolvem outros conhecimentos, valores e atitudes que na constante interação, questionamentos e reformulações de aprendizagem com a natureza, tendo o trabalho como mediador, vão surgindo e dando respostas outras para os problemas que por hora se apresentam.

Se por esse viés o trabalho é histórico, por outro lado, o trabalho também é ontológico, pois é próprio da espécie humana. Somente o homem consegue exercer o trabalho de forma a transferir para o objeto construído características próprias da essência humana, dando formas a natureza bruta lapidando-a de acordo com uma intenção previamente estabelecida cognitivamente. É a partir dessa perspectiva que

Pressupomos o trabalho sob forma exclusivamente humana. Uma aranha executa operações semelhantes às do tecelão, e a abelha supera mais de um arquiteto ao construir sua colmeia. Mas o que distingue o pior arquiteto da melhor abelha é que ele figura na mente sua construção antes de transformá-la em realidade. No fim do processo do trabalho aparece um resultado que já existia antes idealmente na imaginação do trabalhador. Ele não transforma apenas o material sobre o qual opera; ele imprime ao material o projeto que tinha conscientemente em mira, o qual constitui a lei determinante do seu modo de operar e ao qual tem de subordinar sua vontade. E essa subordinação não é um ato fortuito. Além do esforço dos órgãos que trabalham, é mister a vontade adequada que se manifesta através da atenção durante todo o curso do trabalho. E isto é tanto mais necessário quanto menos se sinta o trabalhador atraído pelo conteúdo e pelo método de execução de sua tarefa, que lhe 
oferece, por isso, menos possibilidade de fruir da aplicação das suas próprias forças físicas e espirituais (MARX, 2008, p. 211-212, grifos nosso).

Em termos marxianos, o trabalho é elemento constitutivo único e exclusivamente da espécie humana. Somente os homens conseguem exercer o trabalho enquanto criação humana, pois diferentes dos animais que agem por extintos, e por tanto, não exercem o trabalho mais sim um saber fazer animal que é mecanicamente natural de sua espécie, o homem constrói o objeto primeiramente em sua mente depois põe em movimento seu corpo para materializa-lo enquanto objeto concreto.

Nessa relação de dinamicidade no qual o homem põe em movimento todo o seu corpo e sua mente ocorre o desenvolvimento das mais diversas capacidades humanas momento de constituição da humanidade do homem "porque lhe permite o exercício da engenhosidade, da criatividade, do planejamento e da execução do seu querer [...]" (RODRIGUES, 2012, p. 54).

Então, assumindo que o trabalho é uma categoria histórico ontológica que desperta nos homens atitudes, valores, conhecimentos e habilidades psíquico- motoras, ou seja, constroem e desperta nos homens a materializada ânsia de aprender e saber, e ainda, considerando que no presente texto buscamos nos aproximar da categoria saberes, então fazse necessário problematizarmos o que vem a ser saber.

\section{OS SABERES}

Segundo Grzybowski (1986, 50), saber é:

[...] conjunto de conhecimentos e habilidades, valores e atitudes que são produzidos pelas classes, em uma situação histórica dada de relações, para dar conta dos seus interesses. Trata-se do saber parcial que serve para identificar e unificar uma classe social, lhe dar elementos para se inserir numa estrutura de relações sociais de produção e para avaliar a qualidade de tais relações sociais de produção, e em fím, trata-se de um saber que serve de instrumento de organização e luta.

O saber, nas palavras de Grzybowski (1986), é um conjunto de aprendizado que o homem desenvolve nas suas relações históricas dadas quer essas sejam com a natureza, quer essas sejam com seus pares e que assim formam um conjunto de habilidades, valores e atitudes que permitem com que esse homem use tais saberes a seu favor diante das intempestivas relações que o modo de produção capitalista- lhes impõe, provocando nesse homem a construção de uma gama de conhecimentos que de forma dialética vão 
proporcionando- lhe atitudes questionadoras diante da realidade por eles vivida, e assim, se contrapondo a lógica hegemônica do capital que detendo "o modo de produção da vida material condiciona o desenvolvimento da vida social, política e intelectual em geral" (MARX, 1983, p. 24).

Assim, defendemos que o saber é o resultado das potencialidades que o homem, mediado pelo trabalho e diante das situações concretas de adversidades, afetivas e sociais, desenvolve em suas práticas cotidianas sendo que a cada adversidade que surge o homem, em uma relação dialética, aprimora o saber anteriormente adquirido resultado de relações de adversidades anteriormente enfrentadas ora reformulando e afirmando o saber anterior ora negando esse reformulando outros.

Em termos mais objetivos o saber está ligado diretamente as necessidades humanas, necessidades essas que para podermos entender o saber em seu sentido amplo, não podem deixar de serem consideradas, pelo contrário, por mais básicas que essas sejam: comer, beber, vestir-se e ter um abrigo (MARX \& ENGELS, 2009), são carregadas de saberes que adormecidos no ser dos homens são despertadas e postas em movimento pelo trabalho humano que é o meio pelo qual os homens superam suas intempestivas relações.

Por outro lado, as necessidades humanas que estão diretamente ligadas as produções de saberes não estão soltas, descoladas daquilo que o homem vive no seu dia a dia, ou seja os saberes são produtos das necessidades e essas por sua vez são descobertas e enfrentadas no cotidiano dos homens. Logo, é no cotidiano desses sujeitos e seus grupos, ou no dizer de Marx (1818-1883) de suas classes, que o saber deve ser buscado e entendido. Assim nos esclarece Damasceno (1995, p. 29):

Quando se observa o cotidiano dos grupos populares nota-se com muita clareza que
há uma diversidade de saberes que se intercruzam e se interfecundam nesse espaço.
Alguns destes saberes destacam-se como o saber gestado na experiência do grupo,
ancorado no qual os participantes enfrentam os problemas do dia a dia; o saber
escolar necessário à formação da cidadania, quase sempre negado às camadas
populares, forja-se também, nesse contexto, um "saber social", fruto das lutas do
grupo, originado na contestação, mas que cresce e desenvolve-se com a prática
política e contribui substancialmente para a construção de identidade dos sujeitos
sociais.

Nas palavras de Damasceno (1995) “o saber deve ser buscado no cotidiano dos grupos sociais". Segundo essa autorora é esse o lócus no qual o saber se apresenta e que por tanto é ai que deve ser estudado e entendido. Contudo, há de se considerar que o cotidiano é um complexo que se apresenta ao homem das mais variadas formas exigindo os mais variados 
métodos e soluções aos seus problemas que não seguindo uma linearidade e apresentando características próprias exigem respostas e atitudes próprias e únicas.

Nesse contexto não podemos desconsiderar que diante dos problemas e da complexidade do cotidiano, os homens, ou melhor os grupos humanos, ao buscarem respostas e soluções as suas dificuldades, vão aprendendo a desenvolver as respostas que as situações problemas cotidianas exigem, e nesse desenvolver, os saberes vão se apresentado não só como elementos de respostas mas também como categoria que constitui o social, o político e o cultural dos homens, em outros termos constituindo e fortalecendo o ser dos homens.

Por esse viés os saberes vão despertando no homem atitudes contestadoras das realidades produzidas pelo sistema, provocando também entre esses que vivem cotidianos similares uma maior aproximação permitindo com que os homens se enxerguem a partir do que fazem e a partir do que vivem. Em outros termos, o saber como resultado dos problemas do cotidiano dos grupos sociais servem também para aproximar esses e permitindo surgir uma identidade que se forja através das ações que em comum desenvolvem um determinado grupo social, bem como resultado dos sofrimentos e aflições que atingem esses grupos.

É dessa forma que a relação estabelecida entre trabalho e saber assume uma forma de resistência por parte dos pescadores, pois ao assumirem as atividades pesqueiras, além de irem perpetuando os sabres da pesca já dominados e exercido no cotidiano prático de seu oficio, os pescadores também vão estrategicamente desenvolvendo outros saberes o que dialeticamente demostra que os pescadores negam as interpéreas que o capital impõe em suas vidas prática de trabalho. Assim, afirmamos que a construção dos saberes dos pescadores a partir do trabalho da pesca que em comum desenvolvem, é um processo contraditório, de modo que ao mesmo tempo que os pescadores negam a lógica da produção capitalista, através de suas organizações políticas, culturais, afirmam essa mesma lógica, quando suas produções são comercializadas, e necessitam de insumos tecnológicos produzidos pelos saberes do capital.

\section{OS SABERES DOS PESCADORES DA COLÔNIA Z-16 DE CAMETÁ-PA, CONSTRUÍDO A PARTIR DE SUAS RELAÇÕES COM O MUNDO DO TRABALHO}

Nesta seção buscamos assumir que o trabalho da pesca é elemento formador dos saberes dos trabalhadores da Colônia Z-16 de Cametá- Pa, pois, são elementos resultantes das relações materiais cotidianas vividas por esses trabalhadores e seus ambientes naturais. Diante disso, concordamos com Tardif (2008, p. 17, grifos do autor) quando advoga que: 
[...] o saber do trabalhador não é um saber sobre o trabalho, mas realmente do trabalho, [...]. Estabelecer a distinção entre saber e o trabalho é uma operação analítica de pesquisadores ou de engenheiros do trabalho, mas, para um grande número de ofícios e profissões, essa distinção não é tão clara nem tão fácil no processo dinâmico de trabalho.

Assim como Tardif (2008), não iremos distinguir a categoria saberes e trabalho, haja vista que, consideramos aquele (o saber) um produto deste (do trabalho), na verdade, nossas pretensões e também preocupações estão voltadas para a prática do pescador, ou melhor, o trabalho da pesca que em comum esses sujeitos executam e nessa ação possibilita a construção de saberes. Fazer distinção entre saber e trabalho, como destaca o autor a cima, não é tarefa fácil, porque um está relacionado com o outro, não há trabalho se não houver saber sobre esse trabalho para a sua execução, mas no processo do trabalho há a construção de saberes, portanto, saber e trabalho se inter-relacionaram num processo contínuo, mas ao mesmo tempo dialético. O homem necessita do saber e do trabalho para se apropriar da natureza, essa por sua vez é o lócus fundamental de sua existência. Como menciona Vázquez $(1977,132)$ “ [...] o homem só existe na relação prática com a natureza. Na medida em que estar - e não pode deixar de estar - nessa relação ativa, produtiva com ela, a natureza lhe é oferecida como objeto ou matéria de sua atividade, ou como resultado desta, isto é, como natureza humanizada”. A humanização da natureza somente é possível através do trabalho, esse por sua vez também é saber, exclusivamente humano.

Ao analisar o trabalho dos trabalhadores da Colônia de pescadores artesanais Z-16 de Cametá-Pa como sujeitos construtores de saberes, percebemos que a produção de seus saberes é produto de suas relações históricas a partir de seus trabalhos. É nesse sentido que quando indagamos ao informante (P 4) como se deu a sua relação com o mundo do trabalho, esse nos coloca que

[...] eu acho que foi dos quinze anos, já ia com o meu pai pilotar, remar, jogar rede, e de lá eu acho que não teve mais pai, da pesca eu sei de tudo, sei fazer malhadeira, eu sei fazer matapi, eu sei fazer tarrafa [...] (P4).

Da fala do informante ( $\mathrm{P} 4$ ) depreende-se que desde de muito cedo o trabalho da pesca já se faz presente na vida dos pescadores o que nos possibilita inferir que as relações geradas nas atividades da pesca são práticas que possibilitam nos sujeitos pescadores o desenvolvimento de um saber que desde de tenra idade, já se constitui como prática nas relações cotidianas desses sujeitos. Nesse sentido destaca Vázquez (1977, p. 147) “conhecer é conhecer objetos que se integram na relação entre o homem e o mundo, ou entre o homem e a 
natureza, que se estabelece graças à atividade prática humana". Assim, o homem é o que é a partir da prática, essa por sua vez produto da ação e do conhecimento.

Um outro fator a destacar da fala de (P 4) é a presença da família na construção dos saberes da pesca: "[...] eu acho que foi dos quinze anos, já ia com o meu pai pilotar, remar, jogar rede[...]". Geralmente na pessoa do pai ou avô, que são os sujeitos detentores de um saber que também foi aprendido no passado com seus pais ou avôs, o saber do trabalho da pesca é repassado às novas gerações, através de uma relação de aprendizado que se dá através do cotidiano prático da atividade da pesca, onde os saberes vão se materializando nos pescadores como produto de um fazer/aprender constatativos, pois é ao vivenciar as ações concretas do trabalho que os sujeitos aprendem a dominar as práticas do universo da pesca, e por conseguinte, os saberes dessa advindo.

Nessa perspectiva, o trabalho da pesca, além de se constituir como formador de saberes, também vai perpetuando nas novas gerações um fortalecimento de classe, uma vez que ao se identificarem a partir de um saber comum que é por todos dominado e compartilhado, esses sujeitos acabam garantindo que a tradição e a cultura, que diretamente está ligada ao trabalho que em comum executam, não desapareça diante das "modernas" relações de produção impostas pelo capital e seus pragmáticos modelos de trabalho.

O trabalho da pesca, também permite a compreensão do

[...] saber como sendo evolutivo e cultural porque pessoal /relacional/contextual,
podendo modificar-se com o tempo e a experiência, portanto provisório. O saber é
estruturado sem deixar de estar constantemente em construção, constituindo-se de
sistemas como conjuntos de elementos interdependentes. É afetivo porque relaciona-
se com os sujeitos, a construção dos sujeitos, suas autoimagens, julgamentos e
sentimentos (ZAIDAN, 2003, p. 84).

Refletindo as considerações feito por (ZAIDAN, 2003) observamos que no contexto da Colônia Z-16 de Cametá-Pa, desenvolve-se uma concepção de trabalho de pesca que vem assumindo um processo de relação desenvolvido no âmbito coletivo e pessoal, um processo construído na vivência cotidiana do trabalho, na prática dos sujeitos, nas relações pessoais e impessoais construídas nas suas interações coletivas, envolvendo assim as objetividades, subjetividades, afetividade, as histórias de cada um e do coletivo de forma interdependente.

Assim, é agindo, fazendo, experimentando, que o pescador desenvolve o domínio de sua prática laboral, um saber produzido a partir da realidade que o cerca e que provoca nesses sujeitos, posturas que lhes permitem vencer as adversidades por hora apresentadas. 
Nesse sentido, a construção de saberes vem se apresentado como sínteses da história da qual os pescadores são agentes ativos, pois

Só se é algo mediante um contínuo processo de agir; só se é algo mediante a ação. É o que testemunham todos os entes que se revelam à experiência humana. Mesmo quando se está diante de um objeto puramente material, a sua "essência", como conjunto de características mais ou menos fixas, só tem sentido como capacidade de uma forma de atividade [...] É a ação que delineia, circunscreve e determina a essência dos homens. É na prática pela prática que as coisas humanas efetivamente acontecem, que a história de faz (SEVERINO, 1998, p. 33).

O saber dos trabalhadores da Colônia Z-16 de Cametá- Pa é produto da relação social historicamente estabelecida entre os sujeitos que pescam, a onde a aprendizagem vai se construindo no seio de uma relação do trabalho. Aprendizagem essa que possibilita a perpetuação da espécie, porque as novas gerações vão aprendendo as atividades necessárias para dar conta de viver na realidade que imediatamente dada.

A produção da existência implica o desenvolvimento de formas e conteúdos cuja validade é estabelecida pela experiência, o que configura um verdadeiro processo de aprendizagem. Assim, enquanto os elementos não validados pela experiência são afastados, aqueles cuja eficácia a experiência corrobora necessitam ser preservados e transmitidos às novas gerações no interesse da continuidade da espécie. (SAVIANI, 2007, p. 4-5).

Com essa perspectiva, em uma de nossas entrevistas, ao indagarmos a um de nossos entrevistados se foi difícil construir o instrumento de pesca, obtivemos a seguinte resposta:

\begin{abstract}
Não, não foi difícil porque eu acho que foi a partir dos doze, quatorze anos que o meu pai comprou a primeira malhadeira, daí eu foi prestando atenção no momento que ele ia concertar quando rasgava, prestava atenção, quando ele ia tecer um matapi, quando ia tecer uma tarrafa e eu tava lá perto, aprendi e não tive dificuldade, foi fácil, muito fácil memo. Hoje eu já ensino para outras pessoas, para meus filhos, têm pessoas que vem comigo pedir para ensinar fazer uma "cabeça de tarrafa", eu começo a fazer a cabeça de tarrafa para ele, eu digo: é assim cada carreira de filho você não pode passar para outra malha, você tem que levar até no pé da tarrafa, então a pessoa que presta atenção em poucos dias aprende mesmo (P 2).
\end{abstract}

Olhando para os processos de aprendizagem dos saberes da pesca, a fala de (P 2) é bastante esclarecedora e justifica a firmação de Brandão (2002, p.138) para quem:

[...] o mistério do aprender estende-se como nunca a uma possibilidade polissêmica de descobertas e de integrações de ideais empíricas e teóricas. Uma multiplicidade de olhares e de compreensões que pouco a pouco - a não ser entre raros e arrogantes 
reducionistas - descobre que não há mais caminhos únicos e nem olhares exclusivos.

Assim, podemos dizer que os pescadores produzem seus saberes e que essa produção faz parte de um processo que requer experimentação, análise, reflexão, esforço e dedicação para com suas atividades. Nessa relação, o pescador ultrapassa a circunstância do próprio trabalho, produzindo um saber que ao mesmo tempo é processo e produto de sua relação com o mundo, o que contribui para avançar em sua condição de existência.

Ainda analisando o exposto por (P 2) e assumindo uma perspectiva marxista, podemos depreender que os saberes os quais são dotados os pescadores são resultados da aproximação entre esses sujeitos e o mundo do trabalho. Contudo, mas que simples forma de transmissão de saberes, os aprendizados do oficio de pescador revelam as contradições de um aprendizado que no bojo do movimento dialético mostra as perspectivas pelas quais os saberes do trabalho são assumidos em uma sociedade dualista como a que vive o gênero humano hoje.

Por essa ótica de análise, as contradições do aprender os conhecimentos e saberes que brotam das relações de trabalho, se revelam quando comparamos as perspectivas que os aprendizados do trabalho assumem para o mercado e para os trabalhadores da Z-16.

Para o mercado, o trabalho deve ser ensinado com a perspectiva de perpetuar relações duais onde há uma divisão explicita entre quem pensa e quem executa, ou seja, ensinar/aprender o trabalho para o mercado é se limitar a uma transmissão de conhecimento fragmentada onde o trabalhador não domina as ações do trabalho no todo, mas apenas em parte, partes essas que se restringem meramente ao fazer, executar, não permitindo o pensar, o elaborar e o construir objetiva e subjetivamente as atividades.

Já para os trabalhadores da Colônia Z-16 de Cametá- Pa, as relações que esses sujeitos estabelecem com o trabalho é uma relação que assume uma perspectiva de totalidade ${ }^{8}$, pois, é aprendido em suas múltiplas determinações permitindo a esses sujeitos dominarem o saber e o fazer da pesca de maneira completa. Aos moldes de Adolfo Sánchez Vásquez (1977) o aprender do trabalho para os pescadores se revela enquanto práxis, pois, permite com que aqueles que pescam reflitam sobre suas próprias ações o que lhes possibilita dominarem o trabalho não de forma fragmentada e isolada, mais sim de maneira ampla e total.

É nesse sentido que com os trabalhadores da Colônia Z-16 de Cametá- Pa, vamos encontrar uma forma de atividade desenvolvida por eles mesmos, a pesca, que parece simples de ser praticada, no entanto, possui um contexto amplo de significados, uma vez que envolve 
um conjunto de elementos que proporciona a relação com o mundo em que vivem os pescadores.

Assim, para entendermos como é complexa a relação do trabalho da pesca tomemos a fala do informante (P 3), que explica com detalhes uma das práticas da pesca chamada de rede aberta:

\begin{abstract}
Rede aberta é a rede que pega o mapará, que bloqueia o cardume do peixe, [...], ou seja, cerca um cardume do peixe, depois de cercado bate água para o mapará bater na rede, é isso que se chama de rede aberta, é uma espécie de pescaria, para pegar o peixe em quantidade. Numa rede aberta trabalha em torno de dez a doze pessoas em dois cascos, agora tem o taleiro que ocupa quatro pessoas, tem as pessoas que vão para bater água, essa pescaria utiliza uma base de vinte pessoas, porque é muito peixe, pega-se de peneiros cheiros de peixes.
\end{abstract}

Nessa modalidade de pesca, que é utilizada para a captura do mapará ${ }^{9}$, há um conjunto de atividades que os pescadores desenvolvem. Começa com um pescador experiente que identifica através de uma tala onde está o cardume do peixe, identificado esse, vem o grupo de pescadores para fazer o cerco com a rede, após cercado o peixe, alguns pescadores vão bater água para que o peixe possa se prender na rede de pesca, outros trabalhadores ficam no casco para ajudar colocar a rede com o peixe para dentro de barcos e canoas. É essa modalidade de pesca que se chama rede aberta, é a pesca do mapará (Hypophtholuns adenatus), um peixe típico da região amazônica.

$\mathrm{Na}$ pratica de rede aberta se observa um tipo de saber que é específico dos trabalhadores da pesca, pois para desenvolver essa atividade, esses precisam dominar um conjunto de saberes que são aplicados único e exclusivamente nessa prática.

Assim, o trabalho da pesca constrói um cabedal de saberes que só são desempenhados único e exclusivamente nas atividades da pesca. Atividades que também são sociais, porque necessita da colaboração de um conjunto de trabalhadores, isso sem descartar o processo da comercialização e a forma como cada trabalhador será beneficiado com a produção.

É dessa maneira que os pescadores constroem seus saberes através do trabalho da pesca, tendo como resultado o próprio saber do trabalho, de modo que esse saber assegura sua existência e a garantia dos subsídios mínimos necessários da manutenção de sua vida. O saber não é o fim, mas parte de um processo que se articula em um movimento dialético do qual dinamicamente participam homem, natureza, atividade e finalidade, onde o saber se apresenta como síntese dessas relações. Em outros termos, 
[...] o saber não existe de forma autônoma, pronto e acabado, mas é síntese das relações sociais que os homens estabelecem na sua prática produtiva em detrimento do momento histórico. Assim o trabalho compreendido como todas as formas de atividades humanas pelas quais o homem aprende, compreende e transforma as circunstâncias ao mesmo tempo em que se transforma é a categoria que se constitui no fundamento do processo de elaboração do conhecimento (KUENZER, 1989, p. 183).

Nesse sentido, o saber do trabalhador da pesca é um produto da relação social historicamente estabelecida entre os pescadores e o mundo que os cerca, uma vez que a aprendizagem é construída no seio de uma relação humana a partir do trabalho. Ou seja, o saber do pescador está relacionado com sua história de vida, com sua maneira de trabalhar, de se relacionar com seus pares e com os instrumentos de seu trabalho.

Em linhas gerais, o saber dos pescadores está inter-relacionado ao contexto das atividades de seu trabalho e das relações históricas que vêm construindo de geração a geração. Por tanto, o trabalho tem um papel fundamental no processo de construção dos saberes dos trabalhadores da pesca, de modo que a aprendizagens desses trabalhadores acontecem a partir das vivências com seus pares e desses com a natureza sempre mediado pelo trabalho.

\section{CONSIDERAÇÕES FINAIS}

Partindo da premissa de que o trabalho e os saberes continuam sendo elementos centrais na vida humana, onde aquele (o trabalho), ainda hoje, pode explicar como estar se dado a construção deste (o saber), nesta pesquisa buscamos entender como o mundo do trabalho dos pescadores associados a Colônia de pescadores artesanais Z-16 do município de Cametá, Estado do Pará, estar a materializar nesses sujeitos a construção de um conjunto de saberes.

Assim, foi analisando o trabalho enquanto categoria histórico ontológico de produção humana, ou seja, o trabalho enquanto relação social, que tentamos entender a construção de saberes nos trabalhadores da Colônia Z-16 de Cametá-Pa. Por outro lado, ao buscarmos entender o que são os saberes, tomamos essa categoria, não enquanto construções desprestigiadas e descolada da realidade objetiva na qual os sujeitos estão inseridos, mas sim, enquanto produto de relações histórica das quais os grupos sociais fazem parte.

Nesse sentido, depreendemos que os trabalhadores da Colônia Z-16 de Cametá-Pa constroem seus saberes no contexto de seu trabalho o qual estar articulado ao contexto social. Ou seja, a construção dos saberes dos pescadores está se materializando através de relações 
dinâmicas que esses sujeitos estabelecem com o mundo da pesca do qual participam e na qual estar envolvido um conjunto de elementos entre os quais a cultura, a afetividade, o trabalho, e a própria construção do saber.

Também evidenciaram as contradições que o aprender fazer assume hoje tanto na perspectiva do mercado quanto na perspectiva dos trabalhadores da Colônia Z-16, onde para o mercado, o aprender um oficio se reduz meramente ao domínio de um executar descolado do pensar, e para os trabalhadores da colônia Z-16 de Cametá- Pa, o aprender fazer se dá na perspectiva da totalidade, onde o pescador é o sujeito que domina um fazer que não estar descolado do pensar.

E por fim, ficou evidente que esses saberes são desenvolvidos pelos pescadores ao longo de um processo histórico (SCHWARTZ, 2003), que se inicia geralmente no final da infância e entrada na adolescência, quando esses sujeitos começam a se aproximar do trabalho da pesca a partir das relações que estabelecem com seus familiares, principalmente o pai ou o avô, o que nos permiti afirmar que o trabalho da pesca também perpetua nas novas gerações um fortalecimento de classe, uma vez que ao se identificarem a partir de um saber comum, que é por todos dominado e compartilhado, esses sujeitos acabam garantindo que a tradição e a cultura, que diretamente está ligada ao trabalho que em comum executam, não desapareça diante das "modernas" relações de trabalho imposto pelo capital e seus pragmáticos modelos de trabalho.

\section{REFERENCIAS BIBLIOGRÁFICAS}

BRANDÃO. A educação como cultura. Campinas. São Paulo: Mercado de Letras, 2002.

DAMASCENO, Maria Nobre. O saber social e a construção da identidade. Contexto \& Educação, UNIJUÍ, ano 9, n. 38, p. 19-39, abr./jun. 1995.

FRANCO, Maria Laura P. B. Análise de conteúdo. Brasília: Líber Livro, 2007.

FRIGOTTO, Gaudêncio. Trabalho, conhecimento, consciência e a educação do trabalhador: impasses teóricos e práticos. In: FRIGOTTO, Gaudêncio... [et al.] (Org.). Trabalho e conhecimento: dilemas na educação do trabalhador. -6. ed.- São Paulo: Cortez, 2012. 
GRZYBOWSKI, Cândido. Esboço de uma alternativa para pensar a educação no meio rural. Contexto \& Educação, UNIJUÍ, ano 1, n. 4, p. 47-59, out./dez. 1986.

KUENZER, Pedagogia da fábrica: As relações de produção e a educação do trabalhador. São Paulo: Cortez: Autores Associados, 1989.

MARX, Karl. O capital: crítica da economia política. Livro I. $25^{\mathrm{a}}$ ed.- Rio de Janeiro: Civilização Brasileira, 2008.

. Contribuição à crítica da economia política. São Paulo: Martins Fontes, 1983.

MARX, Karl; ENGELS, F. Estrutura social e formas de consciência. São Paulo: Boitempo, 2009.

MICHELAT, Guy. Sobre a utilização da entrevista não diretiva em sociologia. In: THIOLLENT, Michel. Crítica metodológica, investigação social e enquete operária. São Paulo: Polis, 1985.

RODRIGUES, D. S.; SILVA, G. P. Saberes sociais e luta de classes: um estudo a partir da colônia de pescadores artesanais Z-16 Cametá/ Pará, 2012. Tese (Doutorado em educação) - Universidade Federal do Pará. Instituto de Ciências da Educação. Programa de PósGraduação em Educação. Belém. 2012.

SAVIANI, Demerval. Trabalho e educação: fundamentos ontológicos e históricos. Revista Brasileira de Educação. v.12 n.35 Rio de Janeiro maio/ago. 2007.

SEVERINO, Antônio Joaquim. O conhecimento pedagógico e a interdisciplinaridade: o saber como intencionalização da prática. In: FAZENDA, I.C. Arantes (org). Didática e Interdisciplinaridade. São Paulo: Papirus, 1998.

SCHWARTZ, Yves. Trabalho e Saber. Trabalho \& Educação. Belo Horizonte, n.1, p. 21-34, jun, 2003.

TARDIF, Maurice. Saberes docentes e formação profissional. $9^{\mathrm{a}}$ ed. Petrópolis, Rj: Vozes, 2008. 
VÁZQUEZ, Adolfo Sánchez. Filosofia da Práxis. 2a ed. Rio de Janeiro, Paz e Terra, 1977.

ZAIDAN, Samira. Saberes experienciais e saberes pedagógicos- um estudo. Trabalho \&

Educação. Belo Horizonte, n.1, p. 85-94, jun, 2003. ${ }^{1}$ Especialista em Literatura e Leitura- UFPA. Integrante do Grupo de Estudos e Pesquisa sobre Trabalho e
Educação (GEPTE/UFPA). Aluno do Programa de Pós-Graduação em Educação (PPGED/UFPA) do Curso de
mestrado, da Linha Políticas Públicas Educacionais, sob a orientação do Professor Dr. Gilmar Pereira da Silva.
E-mail: adenil2007ufpaa@yahoo.com.br

${ }^{2}$ Mestre em Educação- UFPA. Integrante do Grupo de Estudos e Pesquisa sobre Trabalho e Educação (GEPTE/UFPA). Aluno do Programa de Pós-Graduação em Educação (PPGED/UFPA) do Curso de Doutorado, da Linha Políticas Públicas Educacionais, sob a orientação do Professor Dr. Ronaldo Marcos de Lima Araujo. Email: egidio@ufpa.br

${ }^{3}$ O município de Cametá, segundo o IBGE (2010) - Instituto Brasileiro de Geografia e Estatística - IBGE, pertence à mesorregião do nordeste paraense e à microrregião Cametá, apresentando uma área correspondente a $3.122 \mathrm{~km}^{2}$. Ainda segundo o (IBGE, 2010), o município apresenta uma população de 120.896 habitantes, dos quais 52.838 encontram-se na zona urbana e 68.058 na zona rural. Trata-se de um município com contingente rural maior do que o urbano (RODRIGUES, 2014, p. 1).

${ }^{4}$ Embora o termo Colônia possa suscitar a imagem de um coletivo de pescadores vivendo da pesca na margem de um rio, trata-se de uma entidade representativa de classe desses sujeitos, reunindo 15.000 associados de diferentes comunidades do município cametaense [...] (Idem).

${ }^{5} \mathrm{O}$ materialismo dialético, [...] é ao mesmo tempo uma filosofia e um método de se fazer ciência. Por ser materialismo e por ser dialético não poderia ter outra lógica que não fosse a própria lógica dialética, uma lógica voltada para o conteúdo do conhecimento, para o concreto (SALOMON, 2000, p. 198).

${ }^{6} \mathrm{O}$ conceito de homem não é um conceito abstrato, a-histórico; pelo contrário, é um conceito concreto. Nessa concepção o homem não se define por uma natureza dada, universal, mas como um devir histórico que se faz, se produz pelo trabalho. A pergunta concreta, histórica, que põem adequadamente a apreensão do conceito de homem não é, pois, o que é o homem, mas como é produzido o homem. O homem concreto é concebido, então como uma síntese das relações sociais que se estabelece na produção de sua existência (FRIGOTTO, 1989, p.72).

${ }^{7}$ A Natureza é concebida como realidade material infinita no espaço e no tempo. Desta realidade surgem os mecanismos que continuam sendo materiais; dos organismos, surgem os processos psíquicos, que são como os organismos também materiais (SALOMON, 2000, p. 197).

${ }^{8}$ [...] a totalidade social construída não é uma racionalização ou modelo explicativo, mas um conjunto dinâmico de relações que passam, necessariamente, pela ação dos sujeitos sociais. Não sendo apenas uma concepção mental, o conceito de totalidade social tem um referencial histórico, material, social, moral ou efetivo, de acordo com as relações que constituem determinada totalidade. Consequentemente, as totalidades são heterogêneas e tão diversificadas quanto os aspectos da realidade (FRIGOTTO \& CIAVATTA, 2001, p. 3).

${ }^{9}$ Mapará (Hypophtholuns adenatus): peixe encontrado nas águas do município do Baixo Tocantins, entre eles, Cametá (DIAS, 2007, p.63).

RECEBIDO EM: Setembro de 2015

APROVADO EM: Abril de 2016 